\title{
CORRECTION
}

\section{Correction: Major QTL confer race-nonspecific resistance in the co-evolved Cronartium quercuum f. sp. fusiforme-Pinus taeda pathosystem}

Edwin Lauer (D) and Fikret Isik (iD)

(c) The Author(s), under exclusive licence to The Genetics Society 2021

Heredity (2021) 127:345; https://doi.org/10.1038/s41437-021-00458-1

Correction to: Heredity https://doi.org/10.1038/s41437-021-004518 , published online 25 June 2021

Unfortunately, the presentation of Eq. 2 was incorrect. The correct Eq. 2 is given below.

$\mathrm{LOD}=\log _{10} \frac{\sum_{i=1}^{n} X_{D} / \sum_{i=1}^{n} Y_{D}}{\sum_{j=1}^{m} X_{R} / \sum_{j=1}^{m} Y_{R}}$ 